\title{
Metabolic responses of the common mussel Mytilus edulis to hypoxia and anoxia
}

\author{
W. X. Wang*, J. Widdows \\ Plymouth Marine Laboratory, Prospect Place, The Hoe, Plymouth PL1 3DH, United Kingdom
}

\begin{abstract}
The effects of hypoxia and anoxia on the metabolic responses of mussels Mytilus edulis of different sizes (spat, $5 \mathrm{~mm}$; juveniles, $13 \mathrm{~mm}$; adults, $33 \mathrm{~mm}$ ) were measured by simultaneous open-flow calorimetry and respirometry. A significant anaerobic contribution to the total metabolic rate of juveniles and adults was only apparent at $P_{\mathrm{O}_{2}}$ (oxygen partial pressure) values $<2.3 \mathrm{kPa}$. In $5 \mathrm{~mm}$ spat, however, the anaerobic component was relatively small and not statistically significant, even at $1.0 \mathrm{kPa}$. At the most severe level of hypoxia $(1.0 \mathrm{kPa})$, the degree to which anaerobiosis contributed towards the total energy metabolism increased with body size from $11 \%$ in spat to $>50 \%$ in adult mussels. These findings contrast with a previous study recording a large anderobic contribution to total metabolism at moderate levels of hypoxia (ca $10 \mathrm{kPa}$ ). The present study showed that the metabolism of juvenile mussels held at $10 \mathrm{kPa}$ for $>50 \mathrm{~h}$ remained fully aerobic. Below $10 \mathrm{kPa}$ the time required to induce a significant anaerobic component declined from ca $42 \mathrm{~h}$ at $4.8 \mathrm{kPa}$ to $5 \mathrm{~h}$ at $1.0 \mathrm{kPa}$. The theat increment' associated with the cost of feeding, digestion and growth was markedly reduced with declining $P_{\mathrm{O}_{2}}$ and was absent under anoxia.
\end{abstract}

\section{INTRODUCTION}

Bivalves are able to tolerate extended periods of hypoxia and anoxia, which may be induced by either shell valve closure or by depletion of oxygen in the surrounding water. Many studies have examined the metabolic responses of mussels Mytilus spp. to declining oxygen tensions $\left(P_{\mathrm{O}_{2}}\right)$ (e.g. Bayne 1971a, b, 1975, Bayne et al. 1976, Bayne \& Livingstone 1977, Famme 1980, Famme et al. 1981, Wang \& Widdows 1991). In these studies the form of the relationship between the rate of oxygen consumption and the declining $P_{\mathrm{O}_{2}}$ appears to vary with experimental (duration of exposure) and biotic conditions (body size, feeding conditions).

Metabolic rate is routinely measured by indirect calorimetric methods, such as respirometry, and rates of oxygen uptake are converted to heat using the standard oxycaloric equivalent of $-450 \mathrm{~kJ} \mathrm{~mol}^{-1} \mathrm{O}_{2}$ (Gnaiger 1983). Respirometric measurements are therefore limited to the quantification of aerobic energy meta-

\footnotetext{
- Present address: Marine Sciences Research Center, State University of New York, Stony Brook, New York 11794-5000. USA
}

bolism, and in order to assess anaerobic metabolism it is necessary to either: (a) estimate heat dissipation based on the stoichiometric analysis of accumulated endproducts of anaerobiosis, or (b) determine the difference between the rates of total heat dissipation and aerobic metabolism using simultaneous calorimetry and respirometry (Gnaiger 1983, Widdows 1987). Famme et al. (1981) used the technique of calorespirometry to determine the total heat dissipation rate and the aerobic metabolic rate, then estimated the anaerobic rate (by difference) of Mytilus edulis in response to declining $P_{\mathrm{O}_{2}}$. In their study they recorded an oxygen-dependent rate of oxygen uptake and a more oxygen-independent rate of heat dissipation, which resulted in a large anaerobic component at intermediate $\mathrm{P}_{\mathrm{O}_{2}}$ levels (i.e. $10 \mathrm{kPa}$ ). To achieve such a high anaerobic metabolic rate (ca $40 \%$ of the total metabolic rate) requires a considerable increase in glycolytic flux (i.e. Pasteur effect), a phenomenon which is considered to be absent in bivalves (De Zwaan 1977, 1983).

The present study employed simultaneous calorimetry and respirometry to (1) examine the effects of factors, such as body size, feeding condition and the duration of exposure, on the relationship between $P_{\mathrm{O}_{2}}$ 
and the total, aerobic and anaerobic rates of metabolism by Mytilus edulis; (2) re-examine the findings of Famme et al. (1981); and (3) assess the wider physiological consequences of hypoxia and anoxia.

\section{MATERIALS AND METHODS}

Three size classes of mussels, namely, spat $(5 \mathrm{~mm}$ shell length, $\mathrm{SL}_{i} 1.3 \mathrm{mg}$ dried weight, DW), juveniles (13 mm SL, $14.7 \mathrm{mg} \mathrm{DW}$ ) and adults (33 mm SL, $140 \mathrm{mg} \mathrm{DW}$ ) were collected (July-August 1989) at neap tide level from a population at Whitsand Bay, Cornwall, England. After the shells were cleaned of epibionts the mussels were held in a tank within an aquarium of recirculating seawater maintained at $15^{\circ} \mathrm{C}$ and 32 ppt salinity. All experiments were conducted at this temperature and salinity. Algal food (Phaeodactylum tricornutum) was dosed by a peristaltic pump to provide a ration above the maintenance requirement for mussels (i.e. $2 \%$ of dry body mass per day). Mussels were acclimatized to such conditions for $1 \mathrm{wk}$ prior to the experimental manipulations and measurements.

Measurements of rates of heat dissipation and oxygen uptake by mussels under normoxia, hypoxia and anoxia (short term). The rates of heat dissipation and oxygen uptake by 3 body sizes of mussels exposed to different levels of oxygen partial pressure were measured by simultaneous open-flow calorimetry and respirometry. Groups of small mussels (i.e. 20 spat, or 4 juveniles) or individual adult mussels were placed in a $25 \mathrm{ml}$ perfusion chamber within a microcalorimeter (LKB 2277 Bioactivity Monitor). A detailed description of the system is given in Widdows (1987). Membranefiltered seawater (FSW, $0.45 \mu \mathrm{m}$ ) was pumped from a reservoir through the perfusion chamber and then to a thermostated Radiometer oxygen sensor (E5046) via $1 \mathrm{~mm}$ bore stainless steel tubing. A duplicate calorespirometric system, but without mussels, acted as a reference system monitoring the baseline of heat flow, the inflow $P_{\mathrm{O}_{2}}$ and the inflow algal cell concentrations (described below). Flow rates between 30 and $62 \mathrm{ml} \mathrm{h}^{-1}$ were selected, depending upon the biomass and rate of oxygen uptake, to achieve a 15 to $20 \%$ removal of $\mathrm{O}_{2}$ from the inflowing water under normoxic conditions. The rates of oxygen uptake were calculated from the difference in oxygen concentration of the outflows from the reference and experimental chambers, at a known flow rate.

The calorimetric system reached a steady state within $3 \mathrm{~h}$ of the mussels being placed in the calorimeter and both rates of heat dissipation and oxygen uptake were continuously monitored for a further 8 to $9 \mathrm{~h}$ (normoxia, $20.7 \mathrm{kPa}$ ). The $P_{\mathrm{O}_{2}}$ level within the reservoir was then decreased in a stepwise manner through $10,5,2,1 \mathrm{kPa}$ and finally to anoxia $(0 \mathrm{kPa})$ by bubbling an appropriate mixture of oxygen and nitrogen gas (supplied by BOC Ltd, London). Anoxia was achieved by bubbling 'oxygen-free' nitrogen gas through the seawater in the reservoir. Each $P_{\mathrm{O}_{2}}$ was maintained for 11 to $13 \mathrm{~h}_{\mathrm{i}}$ therefore, a total of $3 \mathrm{~d}$ was required for each experimental trial. Rates of heat dissipation and oxygen uptake were calculated as integrated average rates over the last $6 \mathrm{~h}$ at each $P_{\mathrm{O}_{2}}$ level. The experimental protocol involved measuring both fed and starved juvenile and adult mussels. The fed condition is described below. The starved condition was achieved following $1 \mathrm{wk}$ starvation in an openflow system with filtered seawater $(1 \mu \mathrm{m})$. However, starved adult mussels held in FSW showed a variable behavioural responses, i.e. extended periods of shell valve closure, which resulted in the cessation of oxygen uptake and very low rates of heat dissipation. Only one successful recording of an 'open' adult mussel with steady rates of heat dissipation and oxygen uptake was obtained. Consequently, only the results for spat (starved, $n=3$ ), juvenile (starved, $n=4$; fed, $\mathrm{n}=4$ ) and adult (fed, $\mathrm{n}=4 ;$ starved, $\mathrm{n}=1$ ) mussels are presented in this paper.

Measurements of ingestion rates by mussels in response to hypoxia and anoxia (short term). Rates of algal cell ingestion by juvenile and adult mussels were measured simultaneously with the rates of heat dissipation and oxygen uptake in the fed groups. Before algal cells (Phaeodactylum tricornutum) were added to the reservoir, they were filtered and resuspended in FSW, thus avoiding any potential effects associated with high concentrations of nutrients of algal exudates in the culture medium (e.g. Ward \& Targett 1989). The algal cell concentration in the reservoir was ca 20000 cells $\mathrm{ml}^{-1}$, and the difference between the inflow and outflow cell concentration (i.e. $>90 \%$ removal) at a known flow rate yielded an ingestion rate of $0.23 \mathrm{mg}$ algae per individual juvenile mussel per day and $1.50 \mathrm{mg}$ algae per individual adult mussel per day under normoxic conditions $\left(10^{6}\right.$ cells $=43.8 \pm 1.2 \mu \mathrm{g}$ (2SE) dry weight; $\mathrm{n}=9$ ). The ingestion rates were calculated by measuring the algal cell concentration in the outflows of the reference and experimental chambers, using a Coulter counter. The flow rates used in the calorespirometric system were optimized for determining the rates of oxygen uptake; but they were too low relative to the pumping rate of the mussels to provide an estimate of the true ventilation (clearance) rate under normoxic and moderate hypoxic (i.e. $\geq 10.4 \mathrm{kPa}$ ) conditions.

Measurements of rates of heat dissipation and oxygen uptake by juvenile mussels during long-term hypoxic exposure. The experimental protocol was similar to that described above. Juvenile mussels (4 
individuals) were measured initially under the normoxic conditions for 8 to $12 \mathrm{~h}$. No algal food was added throughout the period of measurement. The $\mathrm{P}_{2}$ level within the seawater reservoir of the calorespirometric system was then reduced rapidly, by bubbling an appropriate mixture of oxygen and nitrogen gas, to obtain a specific level of $P_{\mathrm{O}_{2}}$. The transition from normoxia to the required $P_{\mathrm{O}_{2}}$ level $(9.7,4.8$ and $2.3 \mathrm{kPa}$ ) normally took about 1 to $1.5 \mathrm{~h}$, whereas at the lowest $P_{\mathrm{O}_{2}}$ $(1.0 \mathrm{kPa})$, it required 3 to $4 \mathrm{~h}$ to reach a steady $P_{\mathrm{O}_{2}}$ level. Each $\mathrm{PO}_{2}$ was then maintained for 45 to $50 \mathrm{~h}$, during which time both the rates of heat dissipation and oxygen uptake were recorded continuously.

After the completion of the calorimetric measurements, the shell length of each mussel was recorded and their body tissues were excised, dried at $90^{\circ} \mathrm{C}$ and weighed.

\section{RESULTS}

\section{Rates of heat dissipation and oxygen uptake by mussels under normoxia, hypoxia and anoxia}

The effects of reduced $P_{\mathrm{O}_{2}}$ on rates of heat dissipation and oxygen uptake by 3 size classes of mussels are presented in Fig. 1A to E. Rates of oxygen uptake are con- verted to energy equivalents using the theoretical oxycaloric equivalent $\left(1 \mu \mathrm{mol} \mathrm{O}_{2} \mathrm{~h}^{-1}=0.450 \mathrm{~J} \mathrm{~h}^{-1}\right)$ for fully aerobic metabolism and divided by body dry mass $\left(\mathrm{J} \mathrm{h}^{-1} \mathrm{~g}^{-1}\right)$. Weight-specific rates of heat dissipation are expressed as $\mathrm{J} \mathrm{h}^{-1} \mathrm{~g}^{-1}$ using a standard conversion factor ( $1 \mathrm{~mW}=3.6 \mathrm{~J} \mathrm{~h}^{-1}$ ) and divided by body dry mass. This enables a direct comparison of measured heat dissipation (= total energy expenditure) with oxygen uptake (= aerobic energy requirement). In general, the relationship between metabolic rate and $P_{\mathrm{O}_{2}}$ was hyperbolic for the 3 size classes measured. The estimated values for critical oxygen partial pressure $\left(P_{\mathrm{c}}\right)$ and the calculated $P_{\mathrm{O}_{2}}$ levels at which rate of heat dissipation declined to $50 \%$ of the normoxic rate are shown in Table $1\left(P_{c}\right.$ is the $P_{\mathrm{O}_{2}}$ level at which metabolic rate becomes oxygen dependent, and here we specifically define it as the $P_{\mathrm{O}_{2}}$ level at which the metabolic rate is significantly depressed compared to that measured under normoxic conditions). All body sizes showed a similar degree of oxygen independence with declining $P_{\mathrm{O}_{2}}$, with no consistent difference in the form of the curves for fed and starved mussels (Fig 1). The differences in $P_{\mathrm{O}_{2}}$ levels resulting in a $50 \%$ reduction of metabolic rate were not statistically significant between the spat and juveniles, but there was a significant difference for adults $(33 \mathrm{~mm})$ and juvenile/spat mussels ( $p<0.05,1$-way ANOVA).
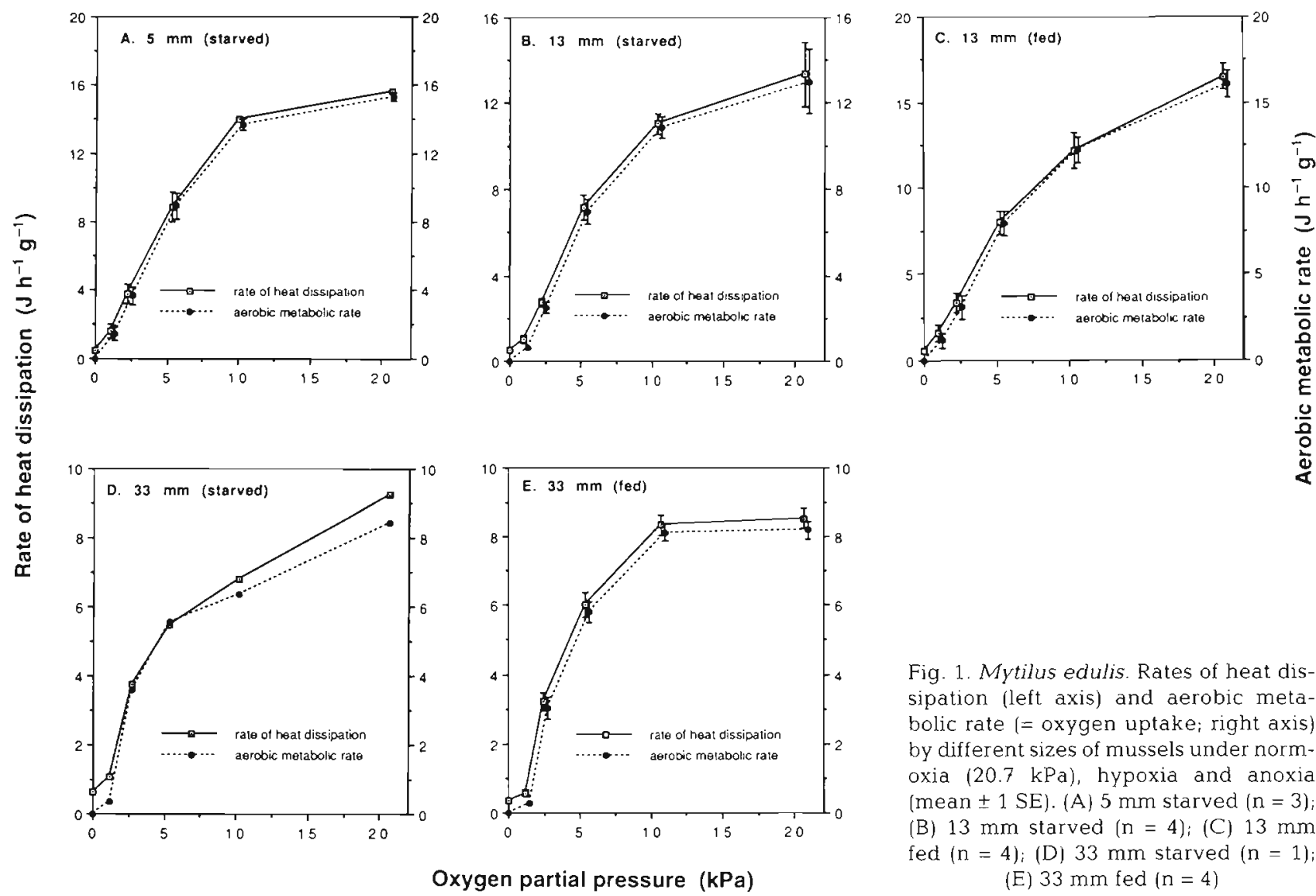

Fig. 1. Mytilus edulis. Rates of heat dissipation (left axis) and aerobic metabolic rate ( $=$ oxygen uptake , right axis) by different sizes of mussels under normoxia $(20.7 \mathrm{kPa})$, hypoxia and anoxia (mean $\pm 1 \mathrm{SE}$ ). (A) $5 \mathrm{~mm}$ starved $(\mathrm{n}=3$ ) (B) $13 \mathrm{~mm}$ starved ( $\mathrm{n}=4)$; (C) $13 \mathrm{~mm}$ fed $(\mathrm{n}=4)_{i}($ D) $33 \mathrm{~mm}$ starved $(\mathrm{n}=1)$; (E) $33 \mathrm{~mm}$ fed $(\mathrm{n}=4)$ 
Table 1. Mytilus edulis. Oxygen-dependence of metabolic parameters for various sizes of mussels (mean $\pm \mathrm{SE}$ ). $P_{c}$ : estimated critical partial pressure; $P_{1}: P_{\mathrm{O}_{2}}$ at which partial anaerobiosis is invoked; $P_{\mathrm{O}_{2}}$ at $50 \%$ of $Q_{\mathrm{nommoxic}}$ : $P_{\mathrm{O}_{2}}$ at which rate of heat dissipation declines to $50 \%$ of the normoxic rate; $Q_{\text {anoxic }} / Q_{\text {normoxic }}$ anoxic rate of heat dissipation as a proportion to normoxic rate of heat dissipation; $n$ : number of replicate measurements

\begin{tabular}{|lccccc|}
\hline & $\begin{array}{c}5 \mathrm{~mm} \\
\text { Starved }\end{array}$ & Starved & Fed & \multicolumn{2}{c}{ Starved } \\
\hline$P_{\mathrm{c}}(\mathrm{kPa})$ & $>10.4$ & $>10.4$ & $>10.4$ & $>10.4$ & $>5.3$ \\
$P_{1}(\mathrm{kPa})$ & $<1.0$ & 2.3 & 2.3 & 1.0 & 1.0 \\
$P_{\mathrm{O}_{2}}$ at $50 \%$ of $Q_{\text {normoxic }}(\mathrm{kPa})$ & $4.73 \pm 0.50$ & $5.03 \pm 0.48$ & $5.83 \pm 0.88$ & 4.0 & $3.50 \pm 0.24$ \\
$Q_{\text {anoxic }} / Q_{\text {normoxic }}(\%)$ & $2.90 \pm 0.30$ & $3.72 \pm 0.42$ & $3.48 \pm 0.58$ & 6.9 & $4.20 \pm 0.23$ \\
$\mathrm{n}$ & 3 & 4 & 4 & 1 & 4 \\
\hline
\end{tabular}

Measured heat equivalents of oxygen uptake for the fed and starved mussels from the 3 size classes (Table 2) indicate that metabolic rates were fully aerobic down to at least $5.3 \mathrm{kPa}$ (i.e. the measured heat equivalent of oxygen uptake was within the theoretical range from -440 to $-480 \mathrm{~kJ} \mathrm{~mol}^{-1} \mathrm{O}_{2}$;

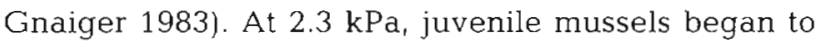
show a slight increase in the measured heat equivalent of oxygen uptake, indicating a small anaerobic component within the total energy metabolism. Spat and adult mussels, however, still maintained a fully aerobic metabolic state. A further reduction in the oxygen partial pressure to $1.0 \mathrm{kPa}$ resulted in a statistically significant $(p<0.05,1$-way ANOVA, compared with normoxic heat equivalent of oxygen uptake) anaerobic contribution to the total energy expenditure with heat equivalent of oxygen uptake $>-680 \mathrm{~kJ} \mathrm{~mol}^{-1} \mathrm{O}_{2}$ for juveniles and adults. At $1.0 \mathrm{kPa}$, spat $(5 \mathrm{~mm})$ had a smaller anaerobic contribution to the total energy metabolism, as shown by the lower heat equivalent of oxygen uptake $\left(-500 \mathrm{~kJ} \mathrm{~mol}^{-1} \mathrm{O}_{2}\right)$. In Table 1 , we also quantify the relative contribution of anaerobic metabolism to the total energy expenditure at $1.0 \mathrm{kPa}$, on the basis of the theoretical oxycaloric equivalent of $-450 \mathrm{~kJ} \mathrm{~mol}-1$ $\mathrm{O}_{2}$ for fully aerobic catabolism. The anaerobic contri- bution to the total energy expenditure at this $P_{\mathrm{O}_{2}}$ level increased with body size, from $11 \%$ in spat $(5 \mathrm{~mm})$ to more than $58 \%$ in adults $(33 \mathrm{~mm})$. The results also showed that both fed and starved individuals had similar heat equivalents of oxygen uptake at $P_{\mathrm{O}_{2}}$ levels $>2.3 \mathrm{kPa}$, suggesting that the relative size of the anaerobic component is independent of the nutritional condition of mussels. However, the heat equivalent of oxygen uptake at $1.0 \mathrm{kPa}$ was higher in the starved group than that recorded in the fed group, presumably brought about by the higher incidence of shell valve closure induced by starvation conditions.

Mean rates of heat dissipation over the last $6 \mathrm{~h}$ of anoxia were expressed as a proportion of the normoxic rates of heat dissipation (Table 1). These ranged from $2.9 \%$ in spat to $4.2 \%$ in adult mussels. The relative levels of anoxic metabolism appear to increase with a $\log$ increase in body size (Fig. 2). This relationship is described by the following equation:

$$
\begin{gathered}
Q_{\text {anoxic }} / Q_{\text {normoxic }}(\%)=2.821+0.626 \log m \\
(r=0.98, \mathrm{n}=4)
\end{gathered}
$$

where $Q_{\text {anoxic }} / Q_{\text {normoxic }}$ is the proportion of anoxic rate of heat dissipation to normoxic rate of heat dissipation $(\%) ; m$ is the biomass (mg).

Table 2. Mytilus edulis. Measured heat equivalent of oxygen uptake $\left(\mathrm{kJ} \mathrm{mol}^{-1} \mathrm{O}_{2}\right)$ under normoxia, hypoxia and anoxia (mean \pm $\mathrm{SEj}$. At $1.0 \mathrm{kPa}$, the contribution of anoxia heat dissipation to the total heat dissipation is indicated in parenthesis. This calcula-

\begin{tabular}{|c|c|c|c|c|c|}
\hline \multirow{2}{*}{$P_{\mathrm{O}_{2}}(\mathrm{kPa})$} & \multirow{2}{*}{$\begin{array}{c}5 \mathrm{~mm} \\
\text { Starved }\end{array}$} & \multicolumn{2}{|c|}{$13 \mathrm{~mm}$} & \multicolumn{2}{|c|}{$33 \mathrm{~mm}$} \\
\hline & & Starved & Fed & Starved & Fed \\
\hline 20.7 & $-461 \pm 5$ & $-462 \pm 5$ & $-463 \pm 7$ & -493 & $-469 \pm 4$ \\
\hline 10.4 & $-461 \pm 3$ & $-457 \pm 3$ & $-445 \pm 12$ & -482 & $-462 \pm 4$ \\
\hline 5.3 & $-449 \pm 5$ & $-463 \pm 7$ & $-453 \pm 9$ & -443 & $-466 \pm 6$ \\
\hline 2.3 & $-464 \pm 3$ & $-509 \pm 29$ & $-502 \pm 33$ & -472 & $-481 \pm 20$ \\
\hline 1.0 & $\begin{array}{c}-500 \pm 30 \\
(11 \%)\end{array}$ & $\begin{array}{c}-742 \pm 83 \\
(41 \%)\end{array}$ & $\begin{array}{c}-682 \pm 81 \\
(34 \%)\end{array}$ & $\begin{array}{l}-1444 \\
(58 \%)\end{array}$ & $\begin{array}{c}-972 \pm 42 \\
(54 \%)\end{array}$ \\
\hline $\mathrm{n}$ & 3 & 4 & 4 & 1 & 4 \\
\hline
\end{tabular}
tion is based on the theoretical value of $-450 \mathrm{~kJ} \mathrm{~mol}^{-1} \mathrm{O}_{2}$ for fully aerobic catabolism. $\mathrm{n}$ : number of replicate measurements 


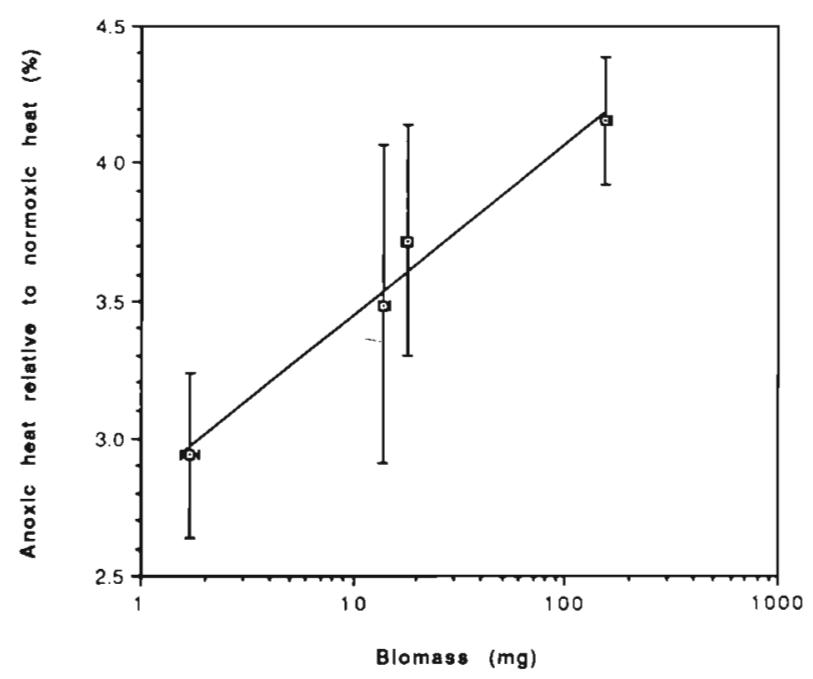

Fig. 2. Mytilus edulis. Proportion of anoxic heat dissipation to normoxic heat dissipation in relation to body size. Mean $\pm 1 \mathrm{SE}$

The metabolic rates of fed and starved juvenile $(13 \mathrm{~mm})$ mussels represent routine and standard metabolic rates, respectively, and the difference between these 2 rates is the 'heat increment' associated with costs of feeding, digestion, food absorption and growth (Table 3). The energetic costs associated with feeding/digestion/ growth declined with a reduction in $P_{\mathrm{O}_{2}}$, from a normoxic value of 3.16 to $0.54 \mathrm{~J} \mathrm{~h}^{-1} \mathrm{~g}^{-1}$ at $P_{\mathrm{O}_{2}}$ levels $\leq 2.3 \mathrm{kPa}$ and then down to negligible values under anoxia.

\section{Ingestion rates by juveniles and adult mussels under hypoxia and anoxia}

Algal ingestion rates by mussels were measured in conjunction with metabolic responses. Feeding activity and ingestion rates by juvenile and adult mussels declined with declining $P_{\mathrm{O}_{2}}$ and ceased under anoxia (Fig. 3). The low perfusion rate in the calorespirometric system relative to the pumping rate of the mussels (e.g.

Table 3. Mytilus edulis. Rates of 'routine' and 'standard' heat dissipation ( $\left.\mathrm{J} \mathrm{h}^{-1} \mathrm{~g}^{-1}\right)$ by $13 \mathrm{~mm}$ juvenile mussels at various levels of $P_{\mathrm{O}_{2}}$. The difference is defined as the 'heat increment' associated with the costs of feeding, digestion and growth

\begin{tabular}{|cccc|}
\hline$P_{\mathrm{O}_{2}}(\mathrm{kPa})$ & $\begin{array}{c}\text { Routine rate } \\
\text { (fed) }\end{array}$ & $\begin{array}{c}\text { Standard rate } \\
\text { (starved) }\end{array}$ & $\begin{array}{c}\text { Energy available for } \\
\text { feeding/digestion/growth }\end{array}$ \\
\hline 20.7 & 16.51 & 13.35 & 3.16 \\
10.4 & 12.19 & 11.06 & 1.13 \\
5.3 & 8.02 & 7.18 & 0.84 \\
2.3 & 3.31 & 2.77 & 0.54 \\
1.0 & 1.57 & 1.03 & 0.54 \\
0 & 0.57 & 0.48 & 0.09 \\
\hline
\end{tabular}

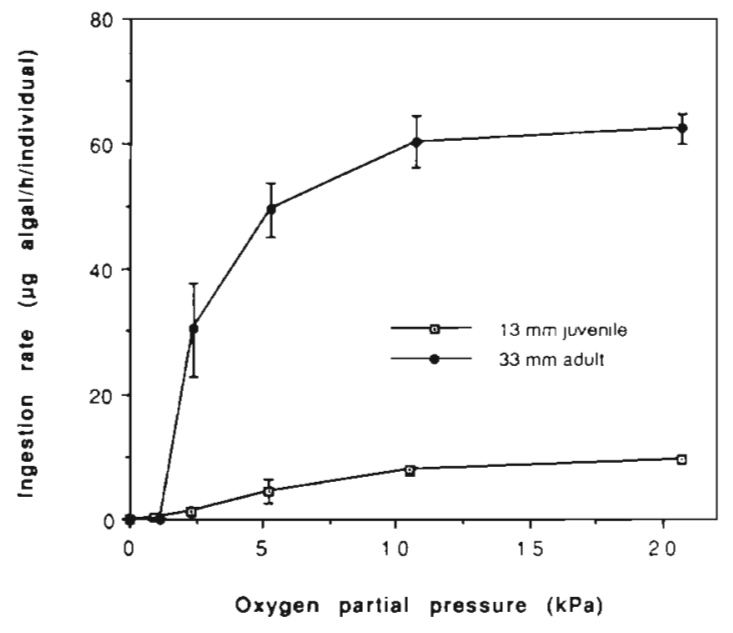

Fig. 3. Mytilus edulis. Algal ingestion rates by $13 \mathrm{~mm}$ juvenile and $33 \mathrm{~mm}$ adult mussels with declining $P_{\mathrm{O}_{2}}$ Mean $\pm 1 \mathrm{SE}$

perfusion rate $0.062 \mathrm{l} \mathrm{h}^{-1}$; pumping rate $>2 \mathrm{l} \mathrm{h}^{-1}$ ), prevented the detection of small changes in the filtration rate or ingestion rate, because there was considerable recirculating of the water through the gills with $>95 \%$ of all inflowing algal cells being removed and ingested by the mussels under normoxia. Consequently, any major reductions in pumping/filtration rate were not detected as significant changes in ingestion rate until $P_{\mathrm{O}_{2}}$ levels declined below 5 to $10 \mathrm{kPa}$. However, below $2.3 \mathrm{kPa}$ and under anoxia there was a cessation of filtering and ingestion activity.

The relationship between rates of heat dissipation and ingestion rate by juvenile and adult mussels over $P_{\mathrm{O}_{2}}$ levels ranging from $10 \mathrm{kPa}$ down to anoxia can be described by the following equations:

$$
\begin{aligned}
Q= & 2.25+15.03 I R(\mathrm{n}=15, \mathrm{r}=0.86) \\
& (13 \mathrm{~mm} \text { juvenile }) \\
Q= & 0.64+16.52 I R(\mathrm{n}=20, \mathrm{r}=0.93)
\end{aligned}
$$$$
\text { (33 } \mathrm{mm} \text { adult) }
$$

where $Q$ is the rate of heat dissipation $\left(\mathrm{J} \mathrm{h}^{-1} \mathrm{~g}^{-1}\right) ; I R$ is ingestion rate ( $\mathrm{mg}$ algal ingested $\mathrm{h}^{-1} \mathrm{~g}^{-1}$ ).

\section{Metabolic responses of juvenile mussels to long-term hypoxia}

The rates of heat dissipation and oxygen uptake by juvenile mussels during long-term hypoxic exposure are shown in Fig. 4. The appearance of anaerobic metabolism was not only $\mathrm{P}_{\mathrm{O}_{2}}$-dependent 

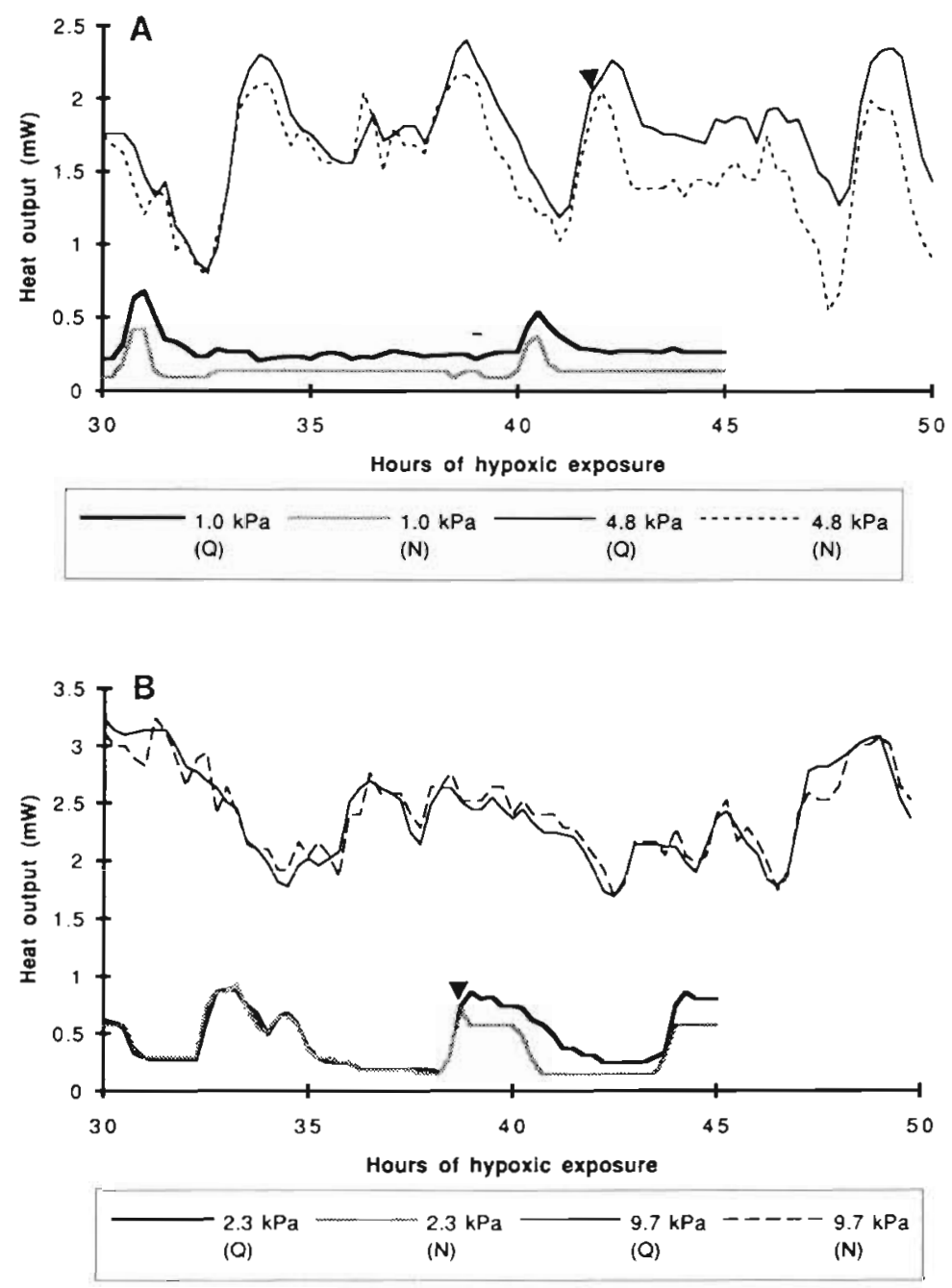

Fig. 4. Mytilus edulis. Superimposed segments of rates of heat dissipation and oxygen uptake by $13 \mathrm{~mm}$ starved juvenile mussels (4 individuals) at various $P_{\mathrm{O}_{2}}$ levels. Rates of oxygen uptake are converted to energy equivalents using a theoretical value of $1 \mathrm{~mol} \mathrm{O}_{2}=0.125 \mathrm{~mW}$ for fully aerobic catabolism. (A) $1.0 \mathrm{kPa}$ (total tissue dried mass $63.58 \mathrm{mg}$, TDW) and $4.8 \mathrm{kPa}$ (TDW $49.14 \mathrm{mg}$ ); (B) $2.3 \mathrm{kPa}$ (TDW $48.89 \mathrm{mg}$ ) and $9.7 \mathrm{kPa}$ (TDW $49.11 \mathrm{mg}$ ). Arrows indicate the onset of a significant anaerobic contribution to the total heat output. $Q$ : rate of heat dissipation; $N$ : rate of oxygen uptake

but also time-dependent. Fully aerobic metabolism was maintained at $9.7 \mathrm{kPa}$ for $>50 \mathrm{~h}$, but this was not the case at lower $P_{\mathrm{O}_{2}}$ levels. During the initial period of hypoxic exposure below $9.7 \mathrm{kPa}$, mussels maintained an essentially aerobic metabolism, but depending upon the $P_{\mathrm{O}_{2}}$ levels, a significant anaerobic metabolic component was subsequently detected. Although it is difficult to identify precisely when anaerobiosis was initiated, owing to the short-term fluctuations in both heat dissipation and oxygen uptake, the calculated values for the heat equivalent of oxygen uptake were consistently and significantly higher than the theoretical value for fully aerobic catabolism after $42,38.5$, and $5 \mathrm{~h}$ at $4.8 \mathrm{kPa}$, $2.3 \mathrm{kPa}$, and $1.0 \mathrm{kPa}$, respectively (Figs. 5 \& 6).

The rates of heat dissipation and oxygen uptake were more variable under hypoxic conditions $(9.7$ to $1.0 \mathrm{kPa}$ ) compared to the rates under normoxia. Such variability probably reflects their behavioural responses to reduced levels of $P_{\mathrm{O}_{2}}$ and the absence of food particles, involving periods of partial closure/inactivity between periods of active pumping. Examination of the power-time curves indicate that rapid changes in heat dissipation were closely coupled to rapid changes in oxygen uptake. Moreover, this activity pattern appeared to be fairly regular at lower $P_{\mathrm{O}_{2}}$ levels, as evinced in Figs. $4 \& 5$. We arbitrarily define a major oscillation as cycle of closure/inactivity with a rapid decline in heat output of $>20 \%$, followed by an open/active phase with higher rates of heat output. Metabolic activity cycles over $10 \mathrm{~h}$ increased gradually from $<1$ to $>3$ with a reduction in $\mathrm{P}_{2}$ levels, reaching a maximum at ca 2.3 to $4.8 \mathrm{kPa}$, followed by a rapid decline at $1.0 \mathrm{kPa}$ and then to zero level under anoxia.

\section{DISCUSSION}

Relationships between body size and oxygen dependence of respiratory rate have been described for several species of bivalves (e.g. Mytilus edulis: Bayne 1971a, Famme 1980; Arctica islandica: Taylor \& Brand 1975; Mulinia lateralis: Shumway 1983). Famme (1980) showed that smaller mussels (M. edulis) had a higher degree of respiratory independence, whereas Taylor \& Brand (1975) and Shumway (1983) showed that the respiratory independence of $A$. islandica and $M$. lateralis increased with increasing body size. Taylor \& Brand (1975) emphasized that bivalves show much intraspecific variation in the degree of respiratory independence in response to reduced $P_{\mathrm{O}_{2}}$ and that this is influenced by abiotic and biotic factors. In the present study there appears to be no clear relationship between body size and the degree of oxygen independence of oxygen uptake and heat dissipation. It is important to note that we measured metabolic rates of mussels under steady state conditions (i.e. $P_{\mathrm{O}_{2}}$ level and feeding regime) for ca $12 \mathrm{~h}$, whereas previous studies have employed a short-term exposure protocol at each $P_{\mathrm{O}_{2}}$ level, or directly measured the metabolic rate in a continuously declining ambient oxygen tension. Furthermore, in these previous studies the rate of oxygen 


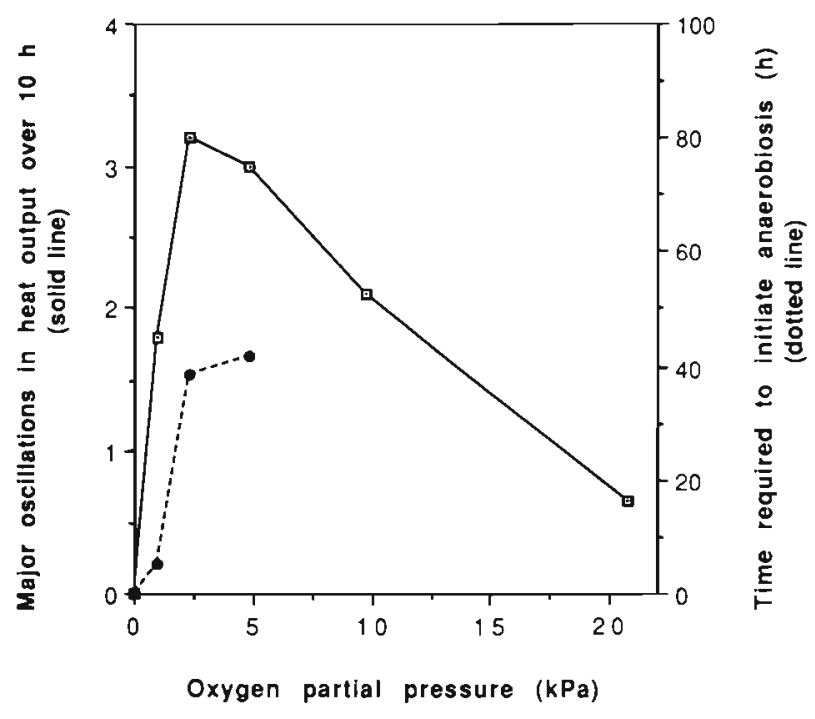

Fig. 5. Mytilus edulis. Time required to initiate a significant anaerobic contribution ( $\bullet---\bullet$ ) and number of major oscillation in the heat output over $10 \mathrm{~h}$ intervals $(\square-\square)$ by $13 \mathrm{~mm}$ starved juvenile mussels during long-term hypoxic exposure. A major oscillation represented a cycle of closure/inactivity with a rapid decline in heat output of $>20 \%$, followed by an open/active phase with higher rates of heat output

uptake will probably have declined during the period of measurement due to the depletion or absence of algal food. For example, in the absence of food the metabolic rate will fall over a period of $3 \mathrm{~h}$ due to the decline in the costs of digestion and growth (Widdows \& Hawkins 1989).

Several studies have used direct calorimetry to measure the total metabolic rate of Mytilus edulis during periods of hypoxia and anoxia, either in water or in gas (Famme et al. 1981, Hammen 1983, Shick et al. 1983, 1986, Widdows \& Shick 1985, reviewed by Widdows 1987, Shick et al. 1988). However, only one study (Famme et al. 1981) has used simultaneous

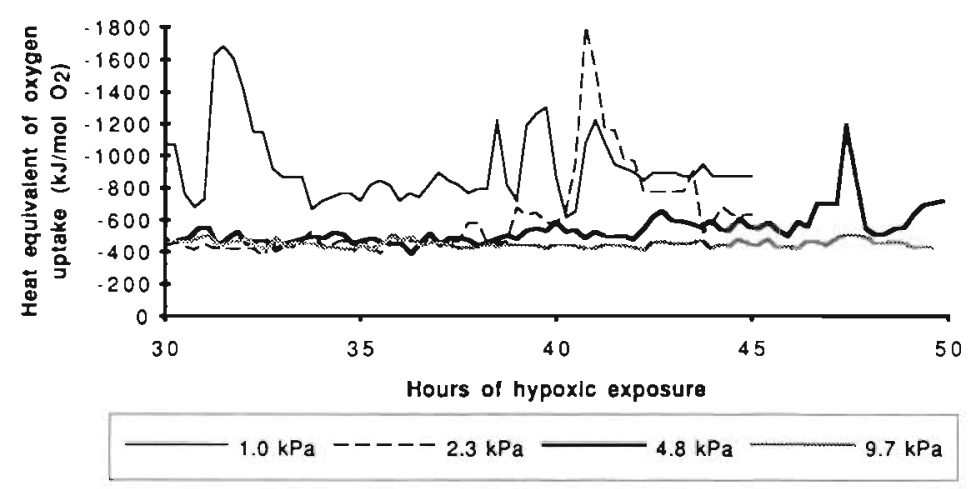

Fig. 6. Mytilus edulis. Instantaneous heat equivalent of oxygen uptake by $13 \mathrm{~mm}$ juvenile mussels at various $P_{\mathrm{O}_{2}}$ conditions. See also Fig. 4 for further explanations calorimetry and respirometry in an attempt to partition total heat dissipation into aerobic and anaerobic components at different $P_{\mathrm{O}_{2}}$ levels. Famme et al. recorded a major increases in the anaerobic component (based on the difference between direct calorimetric and respirometric measurements) in response to moderate hypoxia, reaching a maximum at $P_{\mathrm{O}_{2}}$ values between 5.3 and $10.7 \mathrm{kPa}$. At these $P_{\mathrm{O}_{2}}$ levels, the anaerobic component was high in absolute terms (i.e. $0.1 \mathrm{~J} \mathrm{~h}^{-1}$ ) for a $12 \mathrm{~mm}, 7.6 \mathrm{mg}$ mussel and represented a very high proportion of the total rate of energy metabolism (36 to $84 \%$ ). Above and below this range of $P_{\mathrm{O}_{2}}$ values, the anaerobic component was found to decline and was generally absent under normoxic conditions.

In contrast, the results from the present study demonstrated that at $P_{\mathrm{O}_{2}}$ levels between 5 and $10 \mathrm{kPa}$ there was no significant anaerobic component (Table 2). The rate of anaerobic metabolism in Mytilus edulis was small (<0.004 $\mathrm{J} \mathrm{h}^{-1}$ for a $13 \mathrm{~mm}, 14.7 \mathrm{mg}$ mussel) compared to the aerobic rate $\left(0.12\right.$ to $0.18 \mathrm{~J} \mathrm{~h}^{-1}$ or 8 to $12 \mathrm{~J} \mathrm{~h}^{-1} \mathrm{~g}^{-1}$ ). Anaerobiosis was absent under normoxic conditions and a significant anaerobic component only occurred at a $P_{\mathrm{O}_{2}}$ level below $1 \mathrm{kPa}$ for mussels ranging in size from 5 to $33 \mathrm{~mm}$ (Table 2). Above $2.3 \mathrm{kPa}$, mussels maintained a fully aerobic rate of metabolism, as shown by the measured heat equivalent of oxygen uptake.

No other biochemical or physiological study of Mytilus edulis has obtained such a high anaerobic rate of energy metabolism as that recorded by Famme et al. (1981). However, the cause of this discrepancy is uncertain, as the experimental conditions were largely replicated in the present study. The major feature which accounts for the large anaerobic component in the study by Famme et al. (1981) is the linear and $P_{\mathrm{O}_{2}}$-dependent rate of oxygen uptake. This is in contrast to the relatively oxygen-independent rate of respiration between 20 and $10 \mathrm{kPa}$ recorded in this and most other studies.

A thermodynamic and biochemical interpretation of anaerobiosis suggests that any major involvement of anaerobic pathway to maintain total metabolic activity and thus compensate for any decline in aerobic metabolism will be costly in terms of substrate utilization (Gnaiger 1983, Gnaiger \& Staudigl 1987, Widdows 1987). In order to maintain rates of anoxic ATP production equivalent to the aerobic rates, glycolytic flux would have to increase 8-fold (a Pasteur effect) because of the much lower 'biochemical efficiency' or ATP yield per glycosyl unit in anoxic metabolism (4.71 mol ATP per mol of glycogen; succinate pathwayl compared to aerobic metabolism (37 mol ATP per mol of glycogen). 
In addition, the catabolic heat dissipation per mol of ATP turnover is lower for anoxic than for aerobic metabolism. For aerobic catabolism, the heat equivalent of ATP turnover is $-78 \mathrm{~kJ} \mathrm{~mol}^{-1}$ ATP, and for anoxic catabolism (succinate-propionate pathway) it is $-43 \mathrm{~kJ} \mathrm{~mol}^{-1}$ ATP (Gnaiger 1983). This reduction in anoxic heat effect per unit ATP turnover to ca $55 \%$ of the aerobic value is important for the metabolic interpretation of heat dissipation rates. Under hypoxia, for example, an anaerobic rate of heat dissipation equivalent to $50 \%$ of the normoxic and fully aerobic rate (such as that recorded by Famme et al. 1981) would indicate an anoxic ATP turnover equivalent to $90 \%$ of the normoxic aerobic rate, which when combined with the $50 \%$ aerobic component would result in an ATP turnover $140 \%$ of the normoxic rate. When expressed in terms of substrate utilization, this would amount to a 14-fold increase (i.e. $8 \times 1.8$ ) relative to the aerobic rate. Mytilus edulis is a much-studied euryoxic bivalve, and there is no evidence of a 'Pasteur effect' (i.e. no activation of glycolysis) under environmental hypoxia and anoxia (De Zwaan \& Wijsman 1976, Shick et al. 1983, 1986). Mussels are able to survive long periods of anoxia (i.e. $9.6 \mathrm{~d}$ of median mortality time by 30 to $35 \mathrm{~mm}$ adult mussels; Wang et al. 1992) by inducing metabolic suppression and thereby conserve energy (Shick et al. 1988).

Recently, there have been comparisons made between $P_{c}$ values (critical partial pressure) and $P_{1}$ values (limiting oxygen partial pressure: $P_{\mathrm{O}_{2}}$ level at which partial anaerobic metabolism is invoked) (Pörtner et al. 1985, 1991, Hardewig et al. 1991). Pörtner et al. (1985), by measuring the rate of oxygen uptake and the anaerobic end-products, demonstrated the coincidence of $P_{\mathrm{c}}$ and $P_{l}$ in the marine worm Sipunculus nudus $(6.7 \mathrm{kPa}$ for the large specimens). In the amphibian toad Bufo marinus, $P_{1}$ value coincided with the $P_{\mathrm{O}_{2}}$ level at which oxygen consumption rate was increased (4 to $5 \mathrm{kPa}$ ) (Pörtner et al. 1991). Their studies imply that these 2 parameters may be inter-dependent, enabling animals to initiate anaerobiosis in compensation for a decline in aerobic metabolism induced by a reduction in environmental oxygen.

In this study we define the $P_{\mathrm{c}}$ as the $P_{\mathrm{O}_{2}}$ level at which the metabolic rate is significantly depressed compared to that measured under normoxic conditions. Although this definition is somewhat different from that used by Pörtner et al. (1985), who consider the $P_{\mathrm{c}}$ as the $P_{\mathrm{O}_{2}}$ level below which oxygen consumption is progressively and non-linearly reduced, it appears that a significant depression of the aerobic metabolism in Mytilus edulis is not accompanied by an immediate and significant involvement of anaerobic metabolism when measured by calorespirometric techniques. However, De Zwaan et al. (1991) have recorded similar and relatively higher value for both $P_{1}(8.7 \mathrm{kPa}$, based on the biochemical measurements of anaerobic end-products including succinate and alanine) and $P_{\mathrm{c}}$ (ca $9.8 \mathrm{kPa}$ ) in Mytilus galloprovincialis, compared to Scapharca inaequivalvis $\left(P_{1}=\right.$ $2.9 \mathrm{kPa} ; P_{c}=4.9 \mathrm{kPa}$ ). They suggest that as a result of the higher $P_{c}$ value and the maximum utilization of anaerobic pathways for ATP production at lower $P_{\mathrm{O}_{2}}$ levels (ca $4.6 \mathrm{kPa}$ ) rather than under anoxia, $M$. galloprovincialis is more likely to experience detrimental effects due to hypoxic stress (De Zwaan et al. 1991).

Under conditions of severe hypoxia $(1.0 \mathrm{kPa})$, anaerobic contribution towards total energy metabolism (TEM) increased with body size (Table 2). For adult mussels, it represents $>50 \%$ of the TEM, whereas with spat it forms only $11 \%$ of the TEM. Smaller individuals are therefore able to maintain a higher degree of aerobic metabolism at $1.0 \mathrm{kPa}$, presumably as a result of the higher surface area to volume ratio and the relatively shorter distance for oxygen diffusion. This has also been observed in mussel larval studies (Wang \& Widdows 1991).

Juvenile musseis held under hypoxic conditions have highly variable but coupled rates of heat dissipation and oxygen uptake. A similar phenomenon has been documented in other bivalves such as Arctica islandica, Modiolus demissus (Pamatmat 1980, 1983), as well as in Mytilus edulis (Widdows \& Shick 1985, Shick et al. 1986, Widdows 1987). It is difficult to establish whether the oscillations in heat flux at low $P_{\mathrm{O}_{2}}$ values are associated with changes in shell gape or are the result of variation in ventilatory activity. At $9.7 \mathrm{kPa}$, rates of oxygen uptake and heat dissipation are closely coupled, thus resulting in a relatively constant heat equivalent of oxygen uptake within the range for fully aerobic catabolism (Fig. 6). When mussels are exposed to $P_{\mathrm{O}_{2}}$ below $9.7 \mathrm{kPa}$ for a prolonged period, the instantaneous heat equivalent of oxygen uptake increases as a function of time and the degree of hypoxia, and is generally higher than the theoretical range for fully aerobic catabolism. The continuous monitoring of rates of heat dissipation and oxygen uptake under steady state conditions (Fig. 4) demonstrates that with declining $P_{\mathrm{O}_{2}}$ there is a gradual reduction in the period of exposure required before the onset of a significant anaerobic contribution to the total metabolism.

The anoxic rate of heat dissipation relative to the normoxic rate of heat dissipation ranged from 3 to $6 \%$. This is in good agreement with that measured by Widdows (1987), but is lower than other studies (e.g. 5 to $10 \%$; Famme et al. 1981). A comparable level (i.e. 3\%) was also recorded for the American oyster Crassostrea virginica (16 mm juvenile; Widdows et al. 1989). In contrast, Stickle et al. (1989) recorded a very high anoxic 
rate ( $75 \%$ of normoxic rate) in starved small oysters $C$. virginica. However, this was due to the very low metabolic rate under normoxia, presumably in response to starvation, rather than a high anoxic rate. The degree of metabolic suppression under anoxia is accompanied by the cessation of costly physiological processes, such as feeding and growth (Fig. 3; Table 3). Protein synthesis is a major component of the cost of growth (Hawkins 1985 . Widdows \& Hawkins 1989) and recent studies have confirmed the cessation of protein synthesis under anoxia (Widdows \& Hawkins unpubl.).

The heat increment associated with the costs of feeding, digestion and growth can be estimated from the differences between the heat dissipation rates of fed and starved mussels (see Widdows \& Hawkins 1989). In the present study there is a marked decline in the heat increment from $19 \%$ to $7 \%$ (expressed as a \% of the total metabolic rate under normoxia) between 20.7 and $10.4 \mathrm{kPa}$ (Table 3 ) and this probably reflects a large reduction in growth costs compared to a small reduction in feeding/digestion costs. Between 10.4 and $1.0 \mathrm{kPa}$ the heat increment is small and gradually declines from $7 \%$ to $3 \%$ of the total metabolic rate under normoxia, as the feeding rate declines (Fig. 3). The interpretation of these results in terms of physiological energetics suggests that there will be little energy available for feeding, digestion and growth in juvenile mussels at $P_{\mathrm{O}_{2}}$ levels below at least $10 \mathrm{kPa}$. These conclusions are in agreement with the finding of Wang \& Widdows (1991). In the previous study we showed that the growth rates of $250 \mu \mathrm{m}$ larvae (SL) were inhibited by a $P_{\mathrm{O}_{2}}$ level of $6 \mathrm{kPa}$ and below, and that they became more susceptible to reduced oxygen as development proceeded.

Acknowledgements. We are grateful to the referees for their helpful comments on the manuscript.

\section{LITERATURE CITED}

Bayne, B. L. (1971a). Oxygen consumption by three species of lamellibranch molluscs in declining ambient oxygen tension. Comp. Biochem. Physiol. 40A: 955-970

Bayne, B. L. (1971b). Ventilation, the heart beat and oxygen uptake by Mytilus edulis L. in declining oxygen tension. Comp. Biochem. Physiol 40A: 1065-1085

Bayne, B. L. (1975). Aspects of physiological condition in Mytilus edulis L., with special reference to the effects of oxygen tension and salinity. In: Barnes, H. (ed.) Proc. 9th Eur. Mar. Biol. Symp. Aberdeen University Press, Aberdeen, p. 213-238

Bayne, B. L., Livingstone, D. R. (1977). Responses of Mytilus edulis L. to low oxygen tension: acclimation of the rate of oxygen consumption. J. comp. Physiol. 114: 129-142

Bayne, B. L., Thompson, R. J., Widdows, J. (1976). Physiology. I. In: Bayne, B. L. (ed.) Marine mussels: their ecology and physiology. Cambridge University Press, Cambridge, p. 121-206
De Zwaan, A. (1977). Anaerobic energy metabolism in bivalve molluscs. Oceanogr. mar. Biol. 15: 103-187

De Zwaan, A. (1983). Carbohydrate catabolism in bivalves. In: Hochachka, P. W. (ed.) The Mollusca, Vol. 1, Metabolic biochemistry and molecular biomechanics. Academic Press, New York, p. 137-175

De Zwaan, A., Cortesı, P., Van den Thillart, G., Roos, J., Storey, K. B. (1991). Differential sensitivities to hypoxia by two anoxia-tolerant marine molluscs: a biochemical analysis. Mar. Biol. 111: 343-351

De Zwaan, A., Wijsman, T. C. M. (1976). Anaerobic metabolism in bivalvia (mollusca): characteristics of anaerobic metabolism. Comp. Biochem. Physiol. 54B: 313-324

Famme, P. (1980). Oxygen-dependence of the respiration by the mussel Mytılus edulis L. as function of size. Comp. Biochem. Physiol. 67A: 171-174

Famme, P., Knudsen, J., Hansen, E. S. (1981). The effect of oxygen on the aerobic-anaerobic metabolism of the marine bivalve, Mytilus edulis L. Mar. Biol. Lett. 2: $345-351$

Gnaiger, E. (1983). Heat dissipation and energetic efficiency in animal anoxibiosis: economy contra power. J. exp. Zool. 228: $471-490$

Gnaiger, E., Staudigl, I. (1987). Aerobic metabolism and physiological responses of aquatic oligochaetes to environmental anoxia: heat dissipation, oxygen consumption, feeding, and defecation. Physiol. Zool 60: 659-677

Hammen, C. S. (1983). Direct calorimetry of marine invertebrates entering anoxia states. J. exp. Zool. 228: 397-403

Hardewig, 1., Addink, A. D. F., Grieshaber, M. K., Pörtner, H. O., Van Den Thillart, G. (1991). Metabolic rates at different oxygen levels determined by drect and indirect calorimetry in the oxyconformer Sipunculus nudus. J. exp. Biol. 157: 143-160

Hawkins, A. J. S. (1985). Relationships between the synthesis and breakdown of protein, dietary absorption and turnovers of nitrogen and carbon in the blue mussel, Mytilus edulis. Oecologia 66: 42-49

Pamatmat, M. M. (1980). Facultative anaerobiosis of benthos. In: Tenore, K. R., Coull, B. C. (eds.) Marine benthic dynamics. University of South Carolina Press, Columbia, p. $69-90$

Pamatmat, M. M. (1983). Simultaneous direct and indirect calorimetry. In: Gnaiger, E., Förstner, H. (eds.) Polargraphic oxygen sensors: aquatic and physiological applications. Springer-Verlag, Berlin, p. 167-175

Pörtner, H. O., Heisler, N., Grieshaber, M. K. (1985). Oxygen consumption and mode of energy production in the intertidal worm Sipunculus nudus L.: definition and characterization of the critical $P_{\mathrm{O}_{2}}$ for an oxyconformer. Respir. Physiol. 59: 361-377

Pörtner, H. O., Maclatchy, L. M., Toews, D. P. (1991). Metabolic responses of the toad Bufo marinus to environmental hypoxia: an analysis of the critical $P_{\mathrm{O}_{2}}$. Physiol. Zool. 64: $836-849$

Shick, J. M., De Zwaan, A., De Bont, A. M. T. (1983). Anoxic metabolic rate in the mussel Mytilus edulis $\mathrm{L}$. estimated by simultaneous direct calorimetry and biochemical analysis. Physiol. Zool. 56: 56-63

Shick, J. M., Gnaiger, E., Widdows, J., Bayne, B. L., De Zwaan, A. (1986). Activity and metabolism in the mussel, Mytilus edulis L. during intertidal hypoxia and aerobic recovery. Physiol. Zool. 59: 627-642

Shick, J. M., Widdows, J., Gnaiger, E. (1988). Calorimetric studies of behavior, metabolism and energetics of sessile intertidal animals. A.m. Zool. 28: 161-181

Shumway, S. E. (1983). Factors affecting oxygen consumption 
in the coot clam Mulinia lateralis (Say). Ophelia 22 $143-171$

Stickle, W. B., Kapper, M. A., Liu, L. L., Gnaiger, E., Wang, S. Y. (1989). Metabolic adaptations of several species of crustaceans and molluscs to hypoxia: tolerance and microcalorimetric studies. Biol. Bull. 177: 303-312

Taylor, A. C., Brand, A. R. (1975). Effects of hypoxia and body size on the oxygen consumption of the bivalve Arctica islandica (L.) J. exp. mar. Biol. Ecol. 19: 187-196

Wang, W. X., Widdows, J. (1991). Physiological responses of mussel larvae Mytilus edulis to environmental hypoxia and anoxia. Mar. Ecol. Prog. Ser. 70: 223-236

Wang, W. X., Widdows, J., Page, D. S. (1992). Effects of organic toxicants on the anoxic energy metabolism of the mussel Mytilus edulis. Mar. environ. Res. 34: 327-331

Ward, J E., Targett, N. M. (1989). Influence of marine microalgal metabolites on the feeding behaviour

This article was submitted to the editor of the blue mussel, Mytilus edulis. Mar. Biol. 101 $313-321$

Widdows, J. (1987). Application of calorimetric methods in ecological studies. In: James, A. M. (ed.) Thermal and energetic studies of cellular biological systems. Wright, Bristol, p. 182-215

Widdows, J., Hawkins, A. J. S. (1989). Partitioning of the rate of heat dissipation by Mytilus edulis into maintenance, feeding, and growth components. Physiol. Zool. 62: $764-784$

Widdows, J., Newell, R. I. E., Mann, R. (1989). Effects of hypoxia and anoxia on survival, energy metabolism, and feeding of oyster larvae (Crassostrea virginica, Gmelin). Biol. Bull. 177: 154-166

Widdows, J., Shick, J. M. (1985). Physiological responses of Mytilus edulis and Cardium edule to aerial exposure. Mar. Biol. 85: 217-232

Manuscript first received: January 28, 1993

Revised version accepted: March 24, 1993 